\title{
Short communication: Associations between blood glucose concentration, onset of hyperketonemia, and milk production in early lactation dairy cows
}

\author{
J. Ruoff, S. Borchardt, and W. Heuwieser ${ }^{1}$ \\ Clinic for Animal Reproduction, Faculty of Veterinary Medicine, Freie Universität Berlin Königsweg 65, 14163 Berlin, Germany
}

\begin{abstract}
The objectives of this study were to describe the associations between hypoglycemia and the onset of hyperketonemia (HYK) within the first 6 wk of lactation, to evaluate the effects of body condition score at calving on glucose concentration, and to study the effects of hypoglycemia on milk production. A total of 621 dairy cows from 6 commercial dairy farms in Germany were enrolled between 1 and $4 \mathrm{~d}$ in milk (DIM). Cows were tested twice weekly using an electronic handheld meter for glucose and $\beta$-hydroxybutyrate (BHB), respectively, for a period of $42 \mathrm{~d}$. Hypoglycemia was defined as glucose concentration $\leq 2.2 \mathrm{mmol} / \mathrm{L}$. Hyperketonemia was defined as a $\mathrm{BHB}$ concentration $\geq 1.2 \mathrm{mmol} / \mathrm{L}$. The onset of HYK was described as early onset (first HYK event within the first 2 wk postpartum) and late onset (first HYK event in wk 3 to 6 postpartum). The effect of ketosis status on blood glucose within 42 DIM was evaluated using a generalized linear mixed model. No effect was observed of HYK on glucose concentration in primiparous cows. Multiparous cows with earlyonset HYK had a lower glucose concentration $(-0.21$ $\mathrm{mmol} / \mathrm{L})$ compared with nonketotic cows. Overall, primiparous cows had a lower prevalence and incidence of hypoglycemia than multiparous cows. Hypoglycemia in multiparous cows was associated with higher first testday milk production and 100 DIM milk production. In conclusion, hypoglycemia mainly occurred in multiparous cows with early-onset HYK, whereas primiparous cows were at a lower risk for hypoglycemia.
\end{abstract}

Key words: glucose, $\beta$-hydroxybutyrate, body condition, transition

\section{Short Communication}

During early lactation, the energy requirements of a dairy cow exceed the available energy from feed intake (Jorritsma et al., 2003). Various metabolic and endo-

Received October 31, 2016.

Accepted March 27, 2017.

${ }^{1}$ Corresponding author: w.heuwieser@fu-berlin.de crine adaptations are necessary to provide the increased glucose needed to support milk production during lactation and to process nonesterified fatty acids taken up from mobilization of body stores (Herdt, 2000; Drackley et al., 2001). Those coordinated changes in metabolism of body tissues were described as homeorrhetic regulation and are necessary to support a physiologic state (Bauman and Currie, 1980; Bauman, 2000). During this process, a moderate increase in circulating ketone bodies is considered to be part of a normal metabolic response, whereas a poor adaptive response can lead to an excessive increase in $\mathrm{BHB}$, which can be measured in blood (Duffield et al., 2009).

Two different types of hyperketonemia (HYK) differing in their onset and pathophysiology were hypothesized. Type I ketosis was described as HYK occurring 3 to 6 wk postpartum when milk secretion is so extensive that the demand for glucose exceeds the capacity for glucose production. The plasma levels of glucose and insulin are low, the levels of ketone bodies are high (Holtenius and Holtenius, 1996; Herdt, 2000). Type II was described as ketosis occurring earlier in lactation as a result of excessive body fat mobilization before or at calving. Insulin resistance and an impaired capacity to use glucose play a major role in the pathogenesis of type II ketosis. Blood insulin and glucose concentrations are high, whereas blood ketone concentrations are lower, in type II ketosis than in type I ketosis (Holtenius and Holtenius, 1996; Herdt, 2000).

There is a lack of science-based information that describes the association between hypoglycemia and HYK considering the ketosis classification. Therefore, the objectives of our study were (1) to describe the associations between hypoglycemia and HYK within the first 6 wk of lactation, (2) to evaluate the effects of BCS at calving on glucose concentration, and (3) to evaluate the effects of hypoglycemia on milk production.

The experimental procedures reported herein were conducted with the approval of the Institutional Animal Care and Use Committee of Freie Universität Berlin. Cows were managed according to the guidelines set by the International Cooperation on Harmonisation of Technical Requirements for Registration of Veterinary Medical Products (Hellmann and Radeloff, 2000). 
A retrospective cohort study was performed as part of another field study evaluating the effect of HYK on reproductive performance. The sample size calculation was based on reproductive outcomes not analyzed here. Therefore, the sample size of this study can be considered as a convenience sample. A total of 621 dairy cows from 6 different commercial dairy farms in Germany were included in the trial. All farms kept at least 600 Holstein dairy cows in freestall barns with continuously feeding systems and recorded medical treatments using a computer-based farm management programs (HerdeW, version 5.8, dsp-Agrosoft Ltd., Ketzin, Germany). Annual milk production (ECM: $4.0 \%$ fat and $3.4 \%$ protein) ranged from 8,465 to $10,733 \mathrm{~kg}$. During the transition period, all cows received a close-up and a fresh cow diet that was typical for the northeast region of Germany, using corn silage as the major forage and balanced by a professional nutritional consultant for protein, vitamins, and minerals. The TMR for close-up cows $\left(\mathrm{n}=6 ; \mathrm{NE}_{\mathrm{L}}=1.53 \pm 0.04 \mathrm{Mcal} / \mathrm{kg}\right.$ of $\left.\mathrm{DM}\right)$ and for fresh cows $\left(\mathrm{n}=6 ; \mathrm{NE}_{\mathrm{L}}=1.68 \pm 0.03 \mathrm{Mcal} / \mathrm{kg}\right.$ of DM) consisted of corn silage and grass silage as forage with a corn-, soybean meal-, and canola meal-based concentrate. The TMR was balanced to meet or exceed minimum nutritional requirements for dairy cows (NRC, 2001). None of the herds used anionic salts in the close-up diet as a prevention strategy for milk fever.

Cows were enrolled between 1 and 4 DIM and were tested for BHB and glucose twice weekly (Monday and Thursday) until 42 DIM, resulting in 12 test results per cow. Therefore, the interval between 2 tests was either 3 or $4 \mathrm{~d}$. At each test BCS was determined on a 5 -point scale with 0.25-point increments (Edmonson et al., 1989) by a trained investigator. The term lactation week was used to describe the time of sample collection relative to calving (e.g., lactation wk 0.5 for the first measurement on DIM 1 to 4, lactation wk 1 for the second measurement on DIM 4 to 7 , lactation wk 1.5 for the third measurement on DIM 8 to 11).

The collection of blood samples and the measurement of BHB by an evaluated electronic BHB meter (NovaVet, Nova Biomedical, Waltham, MA; Bach et al., 2016) were described in a study by Mahrt et al. (2015). Hyperketonemia was defined as $\mathrm{BHB} \geq 1.2 \mathrm{mmol} / \mathrm{L}$ (Suthar et al., 2013). The measurement of glucose was conducted with a handheld electronic glucometer (Precision Xtra, Abbott Diabetes Care Inc., Mississauga, ON, Canada), which was evaluated for cow-side use in dairy cattle (Wittrock et al., 2013). A cut-point for blood glucose was determined by Gordon (2013) as blood glucose $\leq 2.2 \mathrm{mmol} / \mathrm{L}$. In that study, animals that had blood glucose concentration $\leq 2.2 \mathrm{mmol} / \mathrm{L}$ at the time of ketosis diagnosis were more likely to cure and produced more milk after treatment. Treatment benefits did not extend to animals with blood glucose $>2.2 \mathrm{mmol} / \mathrm{L}$ at the time of enrollment.

In total, 621 cows (195 primiparous; 426 multiparous) were used for the analysis. Of those, a total of 58 cows had 3 missing glucose or BHB test results (e.g., because they had not been detected on the test day). For the evaluation of prevalence, only cows with at least 10 test results for glucose and BHB, respectively, were considered for analysis $(\mathrm{n}=563)$. For the evaluation of incidence, only cows with all 12 test results for glucose and $\mathrm{BHB}$, respectively, were considered for analysis (n $=417$ ) because incidence is determined relative to a risk period and therefore missing results could falsify the results. A total of 391 and 354 cows had sufficient milk production data available for the analysis of first test-day milk yield and cumulative 100 DIM milk yield, respectively.

Data from the cow-side evaluation of BHB and glucose and data from the on-farm computer system were exported to Excel (Microsoft Corp., Redmond, WA) spreadsheets and analyzed using SPSS for Windows (version 22.0, SPSS Inc., IBM, Ehningen, Germany).

To evaluate the effect of ketosis status (i.e., nonketotic $=$ no HYK event within the first $6 \mathrm{wk}$ of lactation; early onset $=$ first HYK event within the first $2 \mathrm{wk}$; late onset $=$ first HYK event within wk 3 to 6 postpartum) and BCS on blood glucose within 42 DIM, repeated measures ANOVA with first-order autoregressive covariance was performed using the GENLINMIXED procedure of SPSS. The outcome variable was blood glucose $(\mathrm{mmol} / \mathrm{L})$. Cow was the experimental unit and herd was considered as a random effect. According to the model-building strategies described by Dohoo et al. (2009), each parameter considered for the mixed model should be separately analyzed in a univariate model, including the parameter as a fixed factor (i.e., categorical parameter) or covariate (i.e., continuous parameter). Only parameters resulting in univariate models with $P$ $\leq 0.2$ should be included in the final mixed model. The initial model contained the following explanatory variables as fixed effects: ketosis status (nonketotic, early onset, late onset), BCS (1.00 to 5.00) at the first and second BHB test, parity (primiparous vs. multiparous), and farm. Selection of the model that best fit the data was performed by testing each effect separately in a univariate model and finding the model with the lowest value for the Akaike information criterion (AIC) using a backward elimination procedure that removed all variables with $P>0.10$ from the model. Regardless of the significance level, ketosis status was forced to remain in the model.

To evaluate the effect of ketosis status and glucose on milk yield in multiparous cows, linear regression analysis was performed using the GENLINMIXED pro- 
cedure of SPSS. The outcome variable was either first test-day milk yield $(\mathrm{kg} / \mathrm{d})$ or a projection of cumulative $100 \mathrm{~d}$ milk yield $(\mathrm{kg})$. Cow was the experimental unit and herd was considered as a random effect. The initial model contained the following explanatory variables as fixed effects: ketosis and glucose status (nonketotic, hypoglycemia only, HYK only, and both HYK and hypoglycemia) and DIM at test day. Model building and selection of the model that best fit the data were performed as described earlier. Regardless of the significance level, ketosis status was forced to remain in the model. Primiparous cows had a low prevalence and incidence of hypoglycemia, and therefore effects of hypoglycemia on milk production were only evaluated for multiparous cows.

A significant difference between the levels of a classification variable was declared when $P<0.05$, whereas differences between $P \geq 0.05$ and $P \leq 0.10$ were considered a statistical tendency. As the difference in the occurrence of hypoglycemia in primiparous versus multiparous cows was marked, the 2 groups were evaluated separately.

The concentration of serum glucose in primi- and multiparous cows is shown in Figures 1 and 2, respec- tively. The effect of ketosis status on blood glucose concentration within the first $6 \mathrm{wk}$ of lactation was evaluated for primiparous cows $(\mathrm{n}=195)$ and multiparous cows $(\mathrm{n}=426)$, respectively. Multiparous cows with early-onset HYK had a lower glucose concentration $(-0.21 \mathrm{mmol} / \mathrm{L})$ compared with multiparous nonketotic cows ( $\mathrm{SE}=0.10 ; 95 \% \mathrm{CI}:-0.41$ to $-0.01 ; P=$ 0.041). Multiparous cows with late-onset HYK showed no difference in glucose concentration compared with multiparous nonketotic cows $(P>0.1)$. No effect was observed of HYK on glucose concentration in primiparous cows irrespective of their HYK onset $(P>0.1)$. Also, no effect was observed of BCS at calving on glucose concentration in primi- and multiparous cows, respectively $(P>0.05)$. Overall, primiparous cows had a lower prevalence and incidence of hypoglycemia than multiparous cows. In multiparous cows, overall prevalence of hypoglycemia only and of hypoglycemia combined with HYK was 3.9 and $4.9 \%$, respectively. In primiparous cows, overall prevalence of hypoglycemia only and of hypoglycemia combined with HYK was 0.5 and $0.8 \%$, respectively. Peak incidence of hypoglycemia in multiparous cows occurred in lactation wk 1.5, when $13.1 \%$ of cows had their first hypoglycemic test result.

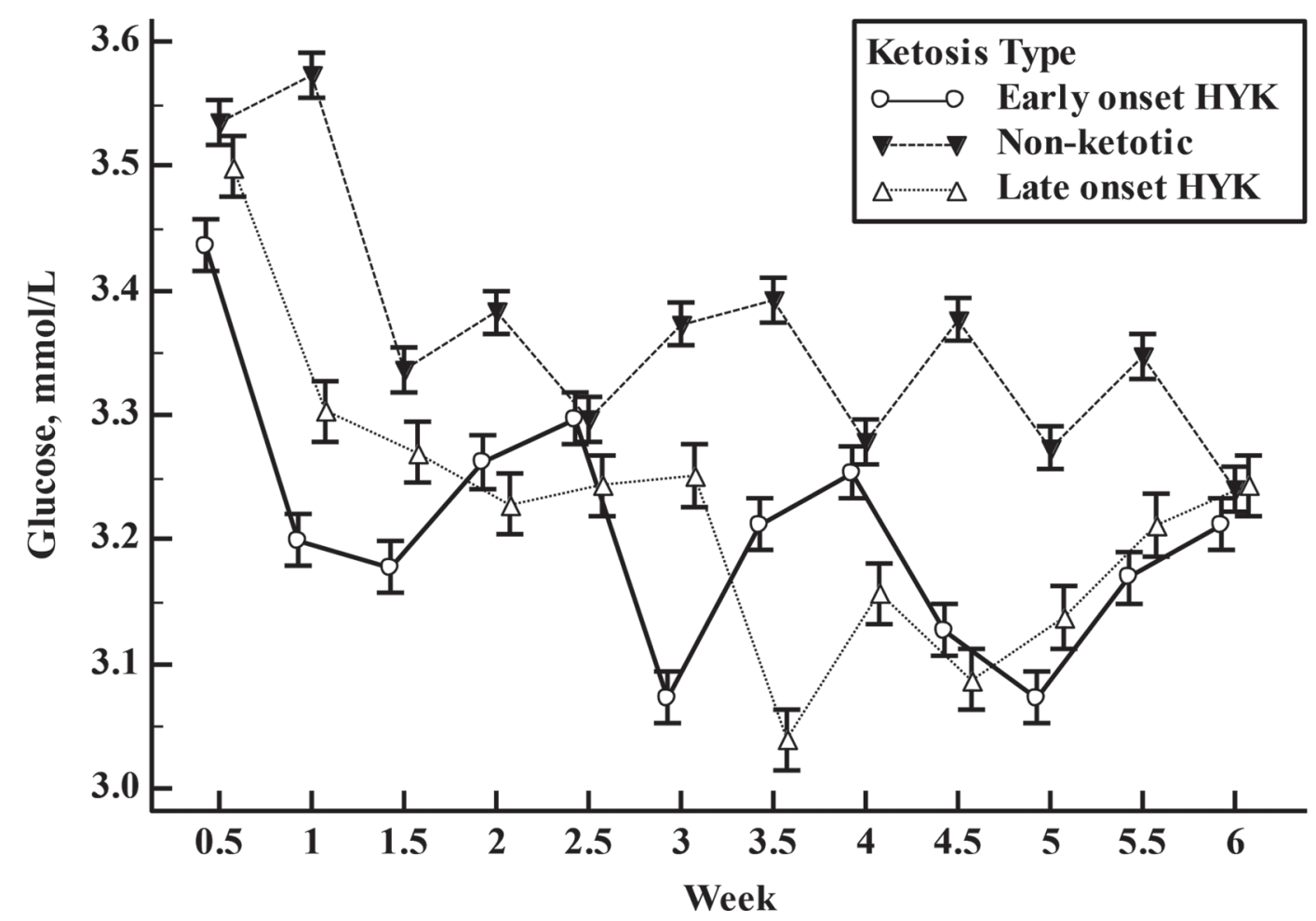

Figure 1. Serum glucose concentrations in primiparous Holstein dairy cows $(\mathrm{n}=195)$ within the first 6 wk of lactation for different ketosis types: nonketotic cows $=$ no hyperketonemia $($ HYK) event within the first 6 wk of lactation; early-onset HYK $=$ first HYK event within the first 2 wk of lactation; late-onset HYK = first HYK event in wk 3 to 6 postpartum. Each data point represents the means for serum glucose concentrations. Error bars represent $95 \%$ CI for the mean. 
Peak incidence of hypoglycemia in primiparous cows occurred in lactation wk 3.5, when $2.4 \%$ of cows had their first hypoglycemic test result.

Estimated means of first test-day milk yield and cumulative 100 DIM milk yield in multiparous cows, stratified by HYK status, are shown in Figure 3. Hypoglycemia was associated with a higher first test-day milk yield as well as with a higher cumulative 100 DIM milk yield. As mentioned above, the effects on milk yield were only evaluated for multiparous cows $(\mathrm{n}=426)$. It has to be noted that in total, $8.2 \%$ of multiparous cows did not have sufficient data for first test-day milk yield and $16.9 \%$ of multiparous cows did not have sufficient data for cumulative 100 DIM milk yield. These cows were not included in the analysis for milk yield, which may have affected our results.

This study was conducted to describe the association between hypoglycemia and the onset of HYK (ketosis type) within the first 6 wk of lactation. To our knowledge, this is the first multi-site study conducted on freestall dairy farms with TMR-fed cows that evaluates the theory of type I and II ketosis by Holtenius and Holtenius (1996).

Our results indicated that the concept of type I and II ketosis cannot be transferred to modern, commercial dairy farms with TMR-fed cows. According to Holtenius and Holtenius (1996), type I ketosis (lactation wk 3 to 6 ) is associated with hypoglycemia. Our results showed that early-onset HYK (lactation wk 1 to 2) was associated with hypoglycemia in multiparous cows, whereas late-onset HYK (lactation wk 3 to 6 ) was not associated with hypoglycemia. Primiparous cows were at lower risk for hypoglycemia than multiparous cows within 6 wk of lactation. Hypoglycemia was associated with higher milk production. Hypoglycemia could mainly be found in multiparous cows in wk 1 to 2 after calving (early-onset HYK) when major physiological, nutritional, metabolic, and immunological changes occur (Bell, 1995; Goff and Horst, 1997; Sordillo and Raphael, 2013). A sudden increase in the demand for hepatic gluconeogenesis is required for milk synthesis and secretion after parturition (Drackley et al., 2001).

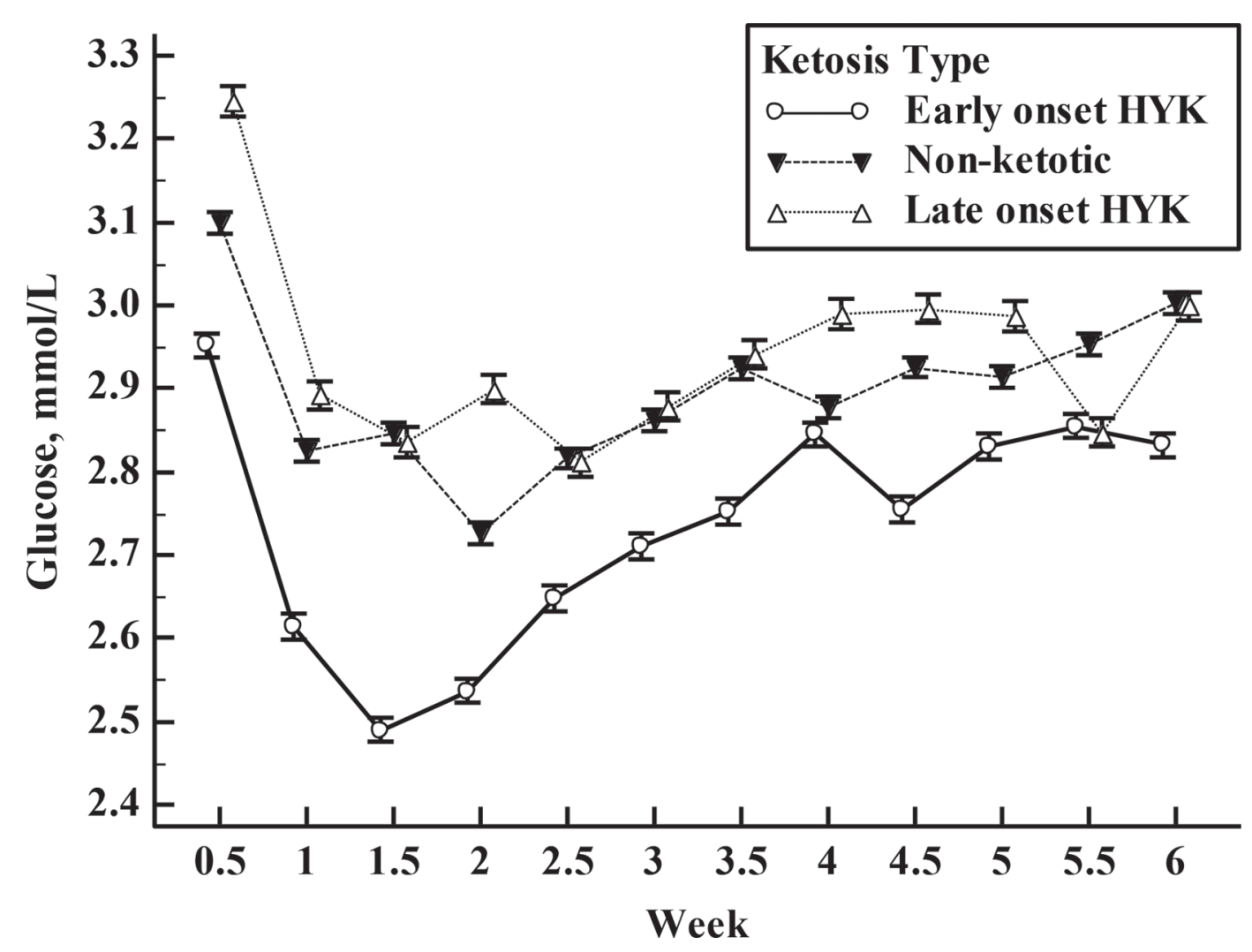

Figure 2. Serum glucose concentrations in multiparous Holstein dairy cows $(\mathrm{n}=426)$ within the first 6 wk of lactation for different ketosis types: nonketotic cows $=$ no hyperketonemia $(H Y K)$ event within the first 6 wk of lactation; early-onset HYK = first HYK event within the first $2 \mathrm{wk}$ of lactation; late-onset HYK = first HYK event in wk 3 to 6 postpartum. Each data point represents the means for serum glucose concentrations. Error bars represent 95\% CI for the mean. 

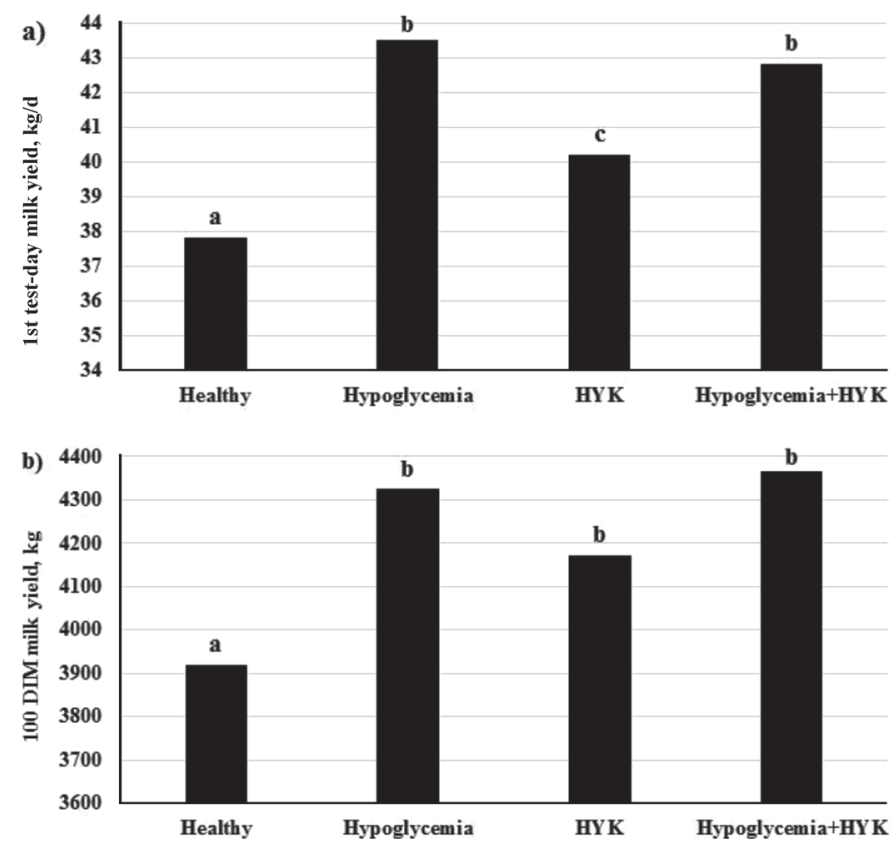

Figure 3. Estimated marginal means of (a) first test-day milk yield $(\mathrm{kg} / \mathrm{d})$ and (b) cumulative 100 DIM milk yield $(\mathrm{kg})$ from the mixed procedure in multiparous cows, stratified by nonketotic and normoglycemic cows $(\mathrm{n}=190 ; \mathrm{n}=174$, respectively), cows with hypoglycemia only $(\mathrm{n}=46 ; \mathrm{n}=40$, respectively), cows with hyperketonemia (HYK) only $(\mathrm{n}=93 ; \mathrm{n}=81$, respectively), and cows with hypoglycemia and HYK $(\mathrm{n}=62 ; \mathrm{n}=59$, respectively) within the first $2 \mathrm{wk}$ of lactation Columns with different letters $(\mathrm{a}-\mathrm{c})$ differ significantly $(P<0.05)$.

But although gluconeogenic pathways in the liver are maximally stimulated, the demand for glucose exceeds the gluconeogenic ability of the liver in that early stage. Changes in the response to insulin have the effect that nonmammary tissues spare glucose to ensure the proper nutrient supply to the mammary gland (Bauman, 2000). Glucose concentration increased after the first 2 wk, although milk production was increasing. We suggest that this could be due to the homeorhetic controls as described by Bauman (2000), leading to an increased liver glucose release as lactation is progressing (Reynolds et al., 2003). In our study, multiparous cows had a lower glucose concentration than primiparous cows, possibly due to a higher metabolic load that overcomes homeostatic regulation.

It remains unclear to which extent cows with earlyonset HYK in combination with hypoglycemia are affected by negative health and production outcomes. As shown in another study (Ruoff et al., 2016), the majority of cows had one HYK event only and a high self-cure rate. It could be possible that those cows are more able to cope with the process of adaptation and an increased BHB concentration could therefore be seen as a sign of a physiological process.
The objective of this study was to evaluate the associations between hypoglycemia and onset of HYK and to evaluate the concept of type I and II ketosis. In conclusion, hypoglycemia mainly occurred in multiparous cows with early-onset HYK. Primiparous cows were less affected by hypoglycemia. It has to be evaluated whether hypoglycemia in high-producing cows leads to negative effects and whether glucose monitoring in addition to BHB should be considered for evaluation of fresh cows.

\section{ACKNOWLEDGMENTS}

J. Ruoff was funded in part by a scholarship from Tiergyn Berlin e.V. (Berlin, Germany).

\section{REFERENCES}

Bach, K. D., W. Heuwieser, and J. A. McArt. 2016. Technical note: Comparison of 4 electronic handheld meters for diagnosing hyperketonemia in dairy cows. J. Dairy Sci. 99:9136-9142. https://doi. org/10.3168/jds.2016-11077.

Bauman, D. 2000. Regulation of nutrient partitioning during lactation: Homeostasis and homeorhesis revisited. Pages 311-328 in Ruminant Physiology: Digestion, Metabolism, Growth and Reproduction. P. B. Cronje, ed. https://doi.org/10.1079/9780851994635.0311.

Bauman, D. E., and W. B. Currie. 1980. Partitioning of nutrients during pregnancy and lactation: A review of mechanisms involving homeostasis and homeorhesis. J. Dairy Sci. 63:1514-1529. https:// doi.org/10.3168/jds.S0022-0302(80)83111-0.

Bell, A. W. 1995. Regulation of organic nutrient metabolism during transition from late pregnancy to early lactation. J. Anim. Sci 73:2804-2819. https://doi.org/10.2527/1995.7392804x.

Dohoo, I. R., S. W. Martin, and H. Stryhn. 2009. Veterinary Epidemiologic Research. 2nd ed. University of Prince Edward Island, Charlottetown, PEI, Canada.

Drackley, J. K., T. R. Overton, and G. N. Douglas. 2001. Adaptations of glucose and long-chain fatty acid metabolism in liver of dairy cows during the periparturient period. J. Dairy Sci. 84(Suppl.):E100E112. https://doi.org/10.3168/jds.S0022-0302(01)70204-4.

Duffield, T. F., K. D. Lissemore, B. W. McBride, and K. E. Leslie. 2009. Impact of hyperketonemia in early lactation dairy cows on health and production. J. Dairy Sci. 92:571-580. https://doi. org/10.3168/jds.2008-1507.

Edmonson, A. J., I. J. Lean, L. D. Weaver, T. Farver, and G. Webster. 1989. A body condition scoring chart for Holstein dairy cows. J. Dairy Sci. 72:68-78. https://doi.org/10.3168/jds.S00220302(89)79081-0.

Goff, J. P., and R. L. Horst. 1997. Physiological changes at parturition and their relationship to metabolic disorders. J. Dairy Sci 80:1260-1268. https://doi.org/10.3168/jds.S0022-0302(97)760557.

Gordon, J. L. 2013. Risk factors for and treatment of ketosis in lactating dairy cattle. DVS Thesis. University of Guelph, Guelph, Canada.

Hellmann, K., and I. Radeloff. 2000. Guidance for industry: Good clinical practice. International Cooperation on Harmonisation of Technical Requirements for Registration of Veterinary Medicinal Products (VICH). VICH, Brussels, Belgium.

Herdt, T. H. 2000. Ruminant adaptation to negative energy balance. Influences on the etiology of ketosis and fatty liver. Vet. Clin. North Am. Food Anim. Pract. 16:215-230. https://doi. org/10.1016/S0749-0720(15)30102-X.

Holtenius, P., and K. Holtenius. 1996. New aspects of ketone bodies in energy metabolism of dairy cows: A review. Zentralbl. Veteri- 
narmed. A 43:579-587. https://doi.org/10.1111/j.1439-0442.1996. tb00491.x.

Jorritsma, R., T. Wensing, T. A. Kruip, P. L. Vos, and J. P. Noordhuizen. 2003. Metabolic changes in early lactation and impaired reproductive performance in dairy cows. Vet. Res. 34:11-26. https:// doi.org/10.1051/vetres:2002054.

Mahrt, A., O. Burfeind, and W. Heuwieser. 2015. Evaluation of hyperketonemia risk period and screening protocols for early-lactation dairy cows. J. Dairy Sci. 98:3110-3119. https://doi.org/10.3168/ jds.2014-8910.

NRC. 2001. Nutrient Requirements of Dairy Cattle. 7th rev. ed. Natl. Acad. Sci., Washington, DC.

Reynolds, C. K., P. C. Aikman, B. Lupoli, D. J. Humphries, and D. E. Beever. 2003. Splanchnic metabolism of dairy cows during the transition from late gestation through early lactation. J. Dairy Sci. 86:1201-1217. https://doi.org/10.3168/jds.S0022-0302(03)737047
Ruoff, J., S. Borchardt, A. Mahrt, and W. Heuwieser. 2016. Effects of hyperketonemia within the first six weeks of lactation on milk production and reproductive performance. J. Adv. Dairy Res. 4:4. https://doi.org/10.4172/2329-888X.1000165.

Sordillo, L. M., and W. Raphael. 2013. Significance of metabolic stress, lipid mobilization, and inflammation on transition cow disorders. Vet. Clin. North Am. Food Anim. Pract. 29:267-278. https://doi. org/10.1016/j.cvfa.2013.03.002.

Suthar, V. S., J. Canelas-Raposo, A. Deniz, and W. Heuwieser. 2013. Prevalence of subclinical ketosis and relationships with postpartum diseases in European dairy cows. J. Dairy Sci. 96:2925-2938. https://doi.org/10.3168/jds.2012-6035.

Wittrock, J. A., T. F. Duffield, and S. J. LeBlanc. 2013. Short communication: Validation of a point-of-care glucometer for use in dairy cows. J. Dairy Sci. 96:4514-4518. https://doi.org/10.3168/ jds.2012-6533. 